\title{
Studi Kinerja Pemeliharaan Taman di Hotel Melia Bali
}

\author{
Nengah Satria Prabawa Putra ${ }^{1}$, Naniek Kohdrata ${ }^{1 *}$, Gusti Alit Gunadi2
}

1. Prodi Arsitektur Lanskap, Fakultas Pertanian, Universitas Udayana, Jl. P.B. Sudirman, Denpasar, Indonesia

2. Prodi Agroekoteknologi, Fakultas Pertanian, Universitas Udayana, Jl. P.B. Sudirman, Denpasar, Indonesia

\author{
*E-mail : naniek_kohdrata@unud.ac.id
}

\begin{abstract}
A Study Of Garden Maintenance Performance In Melia Bali Hotel. Melia Bali Hotel is one of the luxury hotels under Melia Hotel International Corporation. This hotel becomes one of the favorite destinations for tourists during their stay in Bali. This hotel is also often used as a venue for international events. The Melia Bali Hotel concerns on its garden because it is the highest value of the hotel itself. Therefore, the company ought to preserve the garden to embellish and keep the convenience of the hotel environment. This study aims to examine the garden maintenance performance in Melia Bali Hotel. The method used in this current study is a survey method. Data were collected from questionnaire, interview, observation, and literature. Interview was done with several key persons of the garden. Meanwhile, the questionnaire was delivered to twenty garden employees. According to the result of the study, the Melia Bali uses outsourcing garden maintenance crews. The garden crews working performance in maintaining the Melia Hotel garden shows above technical standard performance uses in this study. The maintenance activities are sweeping, watering, and trimming.
\end{abstract}

Keywords: garden maintenance, hotel melia bali, working performance

\section{Pendahuluan}

Hotel Melia Bali terletak di Kawasan Wisata ITDC Lot 1, Nusa Dua, Benoa, Kuta Selatan., Bali. Hotel yang memiliki luas 10 hektar ini berfokus pada taman karena taman merupakan nilai jual utamanya. Mengharuskan pihak hotel melakukan pemeliharaan taman agar kenyamanan serta keindahan taman tetap terjaga. Kepuasan tamu menjadi tujuan utama dari sebuah hotel, hal ini sangat didukung oleh pemeliharaan taman yang baik. Sehingga hasil dari pemeliharaan taman yang baik sangat bepengaruh terhadap citra yang ditampilkan dari sebuah hotel. Salah satu faktor yang berperan untuk menciptakan pemeliharaan taman yang baik adalah kinerja gardener yang efektif dan efisien (Pranata, 2017). Efektif bermakna sasaran kerja tercapai dan efisien berarti ketepatan cara (tidak membuang-buang waktu, tenaga, biaya) daya guna dan kemampuan menjalankan tugas dengan tepat dan baik.

Pemeliharaan taman Hotel Melia Bali menggunakan sistem outsourcing dari perusahaan kontraktor lanskap. Kontraktor yang diajak bekerjasama berperan penuh terhadap semua kegiatan pemeliharaan taman yang digunakan di hotel ini seperti metode yang digunakan, jumlah pegawai, alat-alat yang digunakan, dll. Tentunya, semua itu tetap memerlukan persetujuan dari pihak hotel. Pada Hotel Melia Bali divisi taman sering mendapatkan reward dari pihak hotel. Biasanya, pemberian reward menandakan jika pekerjaan yang dilakukan telah memenuhi syarat yang diberikan. Salah satu cara yang dapat digunakan untuk menilai hasil pemeliharaan adalah dengan menilai efisiensi kinerja gardener. Divisi taman Hotel Melia Bali belum pernah melakukan evaluasi kinerja berdasarkan standar pemeliharaan taman yang ada sehingga kiranya sebuah penelitian tentang efisiensi kinerja gardener yang ada di Hotel Melia Bali dapat dilakukan.

\section{Metode Penelitian}

\subsection{Tempat dan Waktu Penelitian}

Penelitian ini dilakukan pada Hotel Melia Bali, Kawasan Wisata ITDC (Indonesia Tourism Development Corporation) Lot 1, Nusa Dua, Benoa, Kuta Selatan, Bali. Penelitian dilakukan selama 4 bulan yakni bulan November 2019 hingga Februari 2020. Lokasi penelitian dapat dilihat pada Gambar 1. 


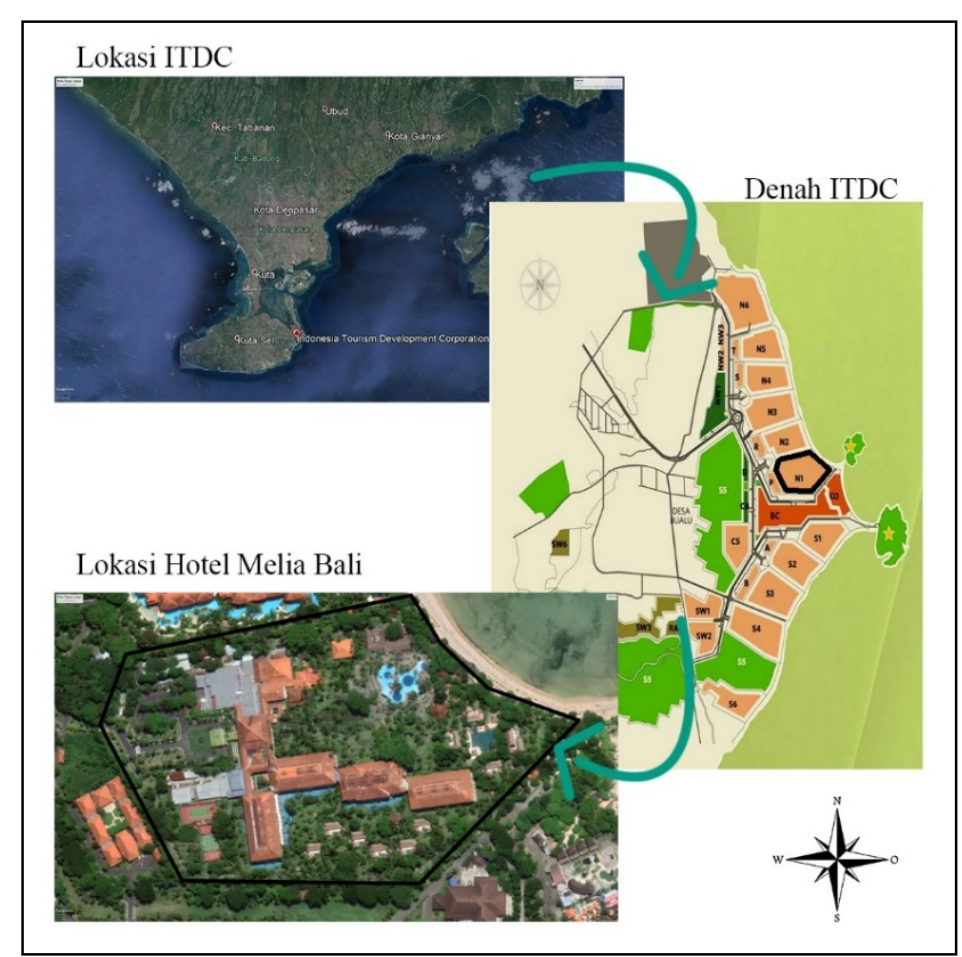

Gambar 1. Lokasi Penelitian (Diolah dari Google Earth, 2019)

\subsection{Alat dan Bahan}

Alat yang digunakan dalam penelitian ini antara lain, kamera handphone berfungsi sebagai penganbil gambar dan perangkat komputer sebagai pengolah data dan bahan yang berupa lembar pertanyaan wawancara kepada koordinator dan 20 lembar kuisioner kepada gardener untuk mengumpulkan data.

\subsection{Jenis dan Sumber Data}

Jenis data yang dikumpulkan dalam penelitian ini berupa data primer dan data sekunder (Tabel 1). Data primer berupa pengumpulan data yang diperoleh secara langsung melalui observasi, wawancara, dan kuisioner. Data sekunder merupakan data yang diperoleh melalui studi pustaka mengenai teori pemeliharaan taman yang efisien dari para ahli, buku-buku, jurnal, dan internet. Menurut Arifin dan Arifin (2005) yang dijadikan acuan kapasitas kerja pemelihara taman dapat dilihat pada Tabel 2. Buku Arifin dan Arifin (2005) digunakan sebagai acuan dikarena berisi standar kapasitas kerja mengenai pemeliharaan taman.

Tabel 1. Jenis Data Inventarisasi

\begin{tabular}{|c|c|c|c|}
\hline No & Data & Sumber & Pengambilan Data \\
\hline \multirow[t]{4}{*}{1.} & Aspek Biofisik & & \\
\hline & a. Letak dan Luas & Lapangan & Studi Pustaka \\
\hline & b. Hidrologi & Lapangan & Wawancara dan Observasi \\
\hline & c. Tanaman & Lapangan & Wawancara dan Observasi \\
\hline \multirow[t]{2}{*}{2.} & Aspek Sosial & & \\
\hline & a. Struktur Organisasi & Lapangan & Wawancara dan Studi Pustaka \\
\hline \multirow[t]{6}{*}{3.} & Aspek Pemeliharaan Taman & & \\
\hline & a. Metode Pemeliharaan & Lapangan & Wawancara dan Studi Pustaka \\
\hline & b. Pelaksanaan Pemeliharaan & Lapangan & Observasi \\
\hline & c. Tenaga Kerja & Lapangan & Wawancara \\
\hline & d. Wilayah Kerja & Lapangan & Kuisioner, Wawancara dan Observasi \\
\hline & e. Alat dan Bahan & Lapangan & Kuisioner, Wawancara dan Observasi \\
\hline
\end{tabular}


Tabel 2. Kapasitas Kerja Operator Pemeliharaan Taman

\begin{tabular}{rll}
\hline No & Jenis Pemeliharaan Taman & Kapasitas Kerja \\
\hline 1 & Pembersihan/penyapuan rumput & $400 \mathrm{~m}$ 2/jam/orang \\
2 & Pembersihan/penyapuan perkerasan & $800 \mathrm{~m}$ 2/jam/orang \\
3 & Penyiraman rumput dengan sprinkler & $500 \mathrm{~m}$ 2/jam/orang \\
4 & Penyiraman rumput dan tanaman penutup tanah & $150 \mathrm{~m}$ 2/jam/orang \\
& dengan selang plastik & 15 pohon/jam/orang \\
5 & Penyiraman pohon dengan selang plastik & $500 \mathrm{~m}$ 2/jam/orang \\
6 & Pemangkasan rumput dengan mesin dorong rover & $250 \mathrm{~m}$ /jam/orang \\
7 & Pemangkasan rumput dengan mesin gendong & $40 \mathrm{~m}^{2} / \mathrm{jam} /$ orang \\
8 & Penyiangan dan penggemburan tanaman semak dan & \\
\hline
\end{tabular}

Rumus dalam penghitungan kapasitas kerja adalah sebagai berikut:

$$
\text { Kapasitas Kerja }(\text { KK })=\quad \text { Waktu } \times \text { Jumlah Pekerja }
$$

Hasil penghitungan kinerja gardener nantinya akan didapatkan melalui hasil akumulasi dari seluruh kinerja gardener di Hotel Melia Bali. Selanjutnya, hasil akumulasi tersebut dirata-ratakan untuk mendapatkan nilai kapasitas kerja gardener.

\subsection{Analisis Data}

Data yang diperoleh dalam penelitian berupa data hasil wawancara dengan pengelola taman dan observasi langsung ke Hotel Melia Bali. Data-data tersebut diolah menggunakan metode analisis deskriptif kuantitatif dan analisis tabulasi. Analisis deskriptif kuantitatif ini digunakan untuk membuat deskripsi, gambaran secara sistematis, faktual dan akurat mengenai hasil obsevasi, wawancara, dan kuisioner yang telah dilakukan. Setelah melalui dua metode tersebut tahap selanjutnya adalah sintesis.

Analisis tabulasi adalah metode pengolahan data yang digunakan dalam mengolah data hasil kuisioner dalam penelitian ini adalah tabulasi data dalam bentuk persentase (\%). Menurut Sudjana (2001), teknik tabulasi data ini digunakan untuk menghitung jumlah pilihan responden $(\mathrm{f})$ dibandingkan dengan jumlah keseluruhan responden $(\mathrm{N})$ ke dalam bentuk persentase (\%) dengan dikali 100 persen. Sintesis merupakan tahapan pemecahan masalah dari obyek penelitian, tujuan sintesis adalah untuk menemukan solusi dari permasalahan pemeliharaan taman yang terdapat di Hotel Melia Bali.

\subsection{Batasan Penelitian}

Lokasi Penelitian dilakukan di kawasan Hotel Melia Bali. Penelitian ini dibatasi pada aspek kegiatan pemeliharaan lanskap pada kawasan Hotel Melia Bali yang meliputi kegiatan menyapu, menyiram, penyiangan, pemupukkan, pendangiran, pemeliharaan hardscape, pemangkasan, serta pengendalian hama dan penyakit.

\section{Hasil dan Pembahasan \\ 3.1 Deskripsi Umum}

Hotel Melia Bali adalah salah satu hotel yang berada di kawasan pesisir di area Indonesia Tourism Development Corporation (ITDC) yang memiliki luas keseluruhan adalah 10 hektar dengan $40 \%$ area terbangun dan $60 \%$ area tidak terbangun. Denah area terbangun dan tidak terbangun dapat dilihat pada Gambar 2. 


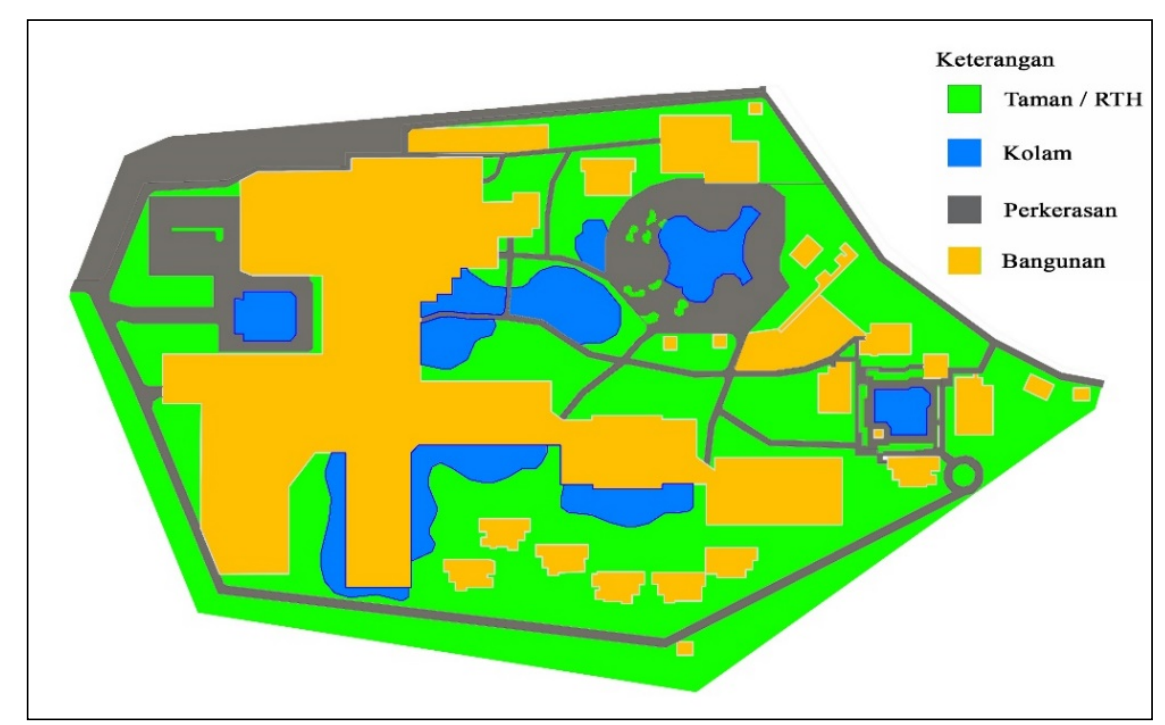

Gambar 2. Denah Area Terbangun Dan Tidak Terbangun (Diolah dari Data Hotel Melia Bali, 2018)

Operasional pemeliharaan taman, Hotel Melia Bali dipimpin oleh seorang chief garden dengan dibantu coodinator, technician dan tiga supervisor. Chief garden merupakan pegawai Hotel Melia Bali sedangkan coodinator, technician dan tiga supervisor merupakan pegawai yang disiapkan oleh pihak kontraktor. Struktur organisasi gardener di Hotel Melia Bali dapat dilihat pada Gambar 3 sebagai berikut:

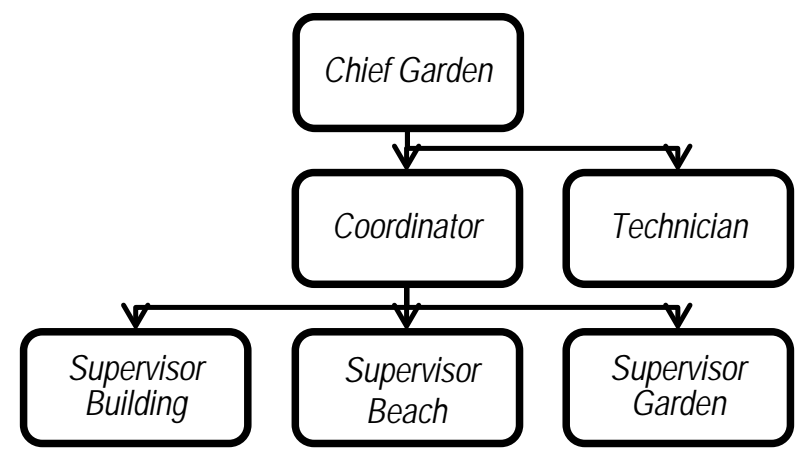

Gambar 3. Struktur Organisasi Gardener Hotel Melia Bali (Data Hotel Melia Bali, 2018)

\subsection{Tanaman di Hotel Melia Bali}

Hotel Melia Bali memiliki berbagai macam jenis tanaman yang digunakan pada areal taman mereka. Bebagai jenis tanaman juga dapat mempengaruhi perlakuan yang diberikan dalam pemeliharaan tanaman tersebut. Pemeliharaan tanaman mencakup hal-hal seperti membersihkan sampah dedaunan, penyiraman, pemangkasan, penyemprotan hama, dan pemupukkan. Berbagai jenis tanaman yang digunakan oleh Hotel Melia Bali dapat dilihat pada Tabel 3.

Tabel 3. Jenis Tanaman di Hotel Melia Bali

\begin{tabular}{lllll}
\hline No & Nama Tanaman & Nama Latin & Jenis Tanaman & $\begin{array}{l}\text { Tinggi } \\
\text { Tanaman }\end{array}$ \\
\hline 1 & Simbar menjangan & Platycerium bifurcatum & Epifit & $0,50-0,75 \mathrm{~m}$ \\
2 & Alamanda & Allamanda cathartica & Merambat & $0,75 \mathrm{~m}$ \\
3 & Palem bismarkia & Bismarckia nobilis & Palem & $1,50 \mathrm{~m}$ \\
4 & Palem ekor tupai & Wodyetia bifurcata & Palem & $3,00 \mathrm{~m}$ \\
5 & Palem jepang & Ptychosperma macarthuri & Palem & $3,00 \mathrm{~m}$ \\
6 & Alang-alang hijau & Pennisetum alopecuroides & Penutup Tanah & $0,35 \mathrm{~m}$ \\
\hline
\end{tabular}




\begin{tabular}{cllll}
\hline No & Nama Tanaman & Nama Latin & Jenis Tanaman & $\begin{array}{l}\text { Tinggi } \\
\text { Tanaman }\end{array}$ \\
\hline 7 & Alang-alang merah & Pennisetum seiaceum & Penutup Tanah & $0,35 \mathrm{~m}$ \\
8 & Anggrek tanah & Bletilla striata & Penutup Tanah & $0,40 \mathrm{~m}$ \\
9 & Andong & Cordyline fruticosa & Perdu & $0,75 \mathrm{~m}$ \\
10 & Andong jagasatru & Cordyline jagasatru & Perdu & $1,00 \mathrm{~m}$ \\
11 & Asoka & Saraca asoco & Perdu & $3,00 \mathrm{~m}$ \\
12 & Alpukat & Persea americana & Pohon & $1,50 \mathrm{~m}$ \\
13 & Ancak & Hemandia pelata & Pohon & $3,00 \mathrm{~m}$ \\
14 & Anggur laut & Coccoloba uvifera & Pohon & $3,00 \mathrm{~m}$ \\
15 & Akalipa & Acalypha wilkesiana & Semak & $0,75 \mathrm{~m}$ \\
16 & Anthorium & Anthurium sp & Semak & $0,70 \mathrm{~m}$ \\
17 & Ararea & Osmoxylon lineare & Semak & $0,40 \mathrm{~m}$ \\
18 & Keladi air hijau & Colocasia esculenta & Tanaman Air & $0,50 \mathrm{~m}$ \\
19 & Keladi air merah & Colocasia black magic & Tanaman Air & $0,50 \mathrm{~m}$ \\
20 & Melati air & Echinodorus palaefollus & Tanaman Air & $0,50 \mathrm{~m}$ \\
\hline
\end{tabular}

Sumber: Hotel Melia Bali (2018)

\subsection{Sistem dan Konsep Pemeliharaan Taman}

Sistem pemeliharaan taman yang digunakan adalah dengan alih daya (outsourcing). Dalam perjanjian yang dibuat, pihak kontraktor menyediakan berbagai kebutuhan alat, bahan dan tenaga kerja yang diperlukan untuk pelaksanaan pemeliharaan. Sistem pemeliharaan unit atau zona adalah pemeliharaan yang berdasarkan pada zona-zona taman yang telah di bagi oleh pihak kontraktor, disetiap zona akan ada yang pekerja yang bertanggung jawab atas zona itu. Zona tersebut terdiri dari main entrance, main pool, sateria, top lagoon, wedding bale and villa pool, area building, lagoon asc, area villa $(7,8,9,10)$, area villa $(6,5,4)$, area tennis, beach, dan yhi spa serta parking. Selanjutnya sistem pemeliharaan khusus adalah sistem pemeliharaan yang berdasarkan pada keahlian dari pegawai itu sendiri, seperti: memotong atau memangkas rumput yang dilakukan 2 orang dan memangkas pohon yang dilakukan 3 orang.

Ketut Suarjana koordinator gardener mengatakan menerapkan konsep pemeliharaan ideal dan pemeliharaan fisik. Pemeliharaan ideal mengacu pada desain awal yang mengambil konsep Green atau hijau, dimana semua area harus terlihat hijau, sejuk, dan rapi. Konsep itu diterapkan pada seluruh area lanskap hotel walaupun area itu merupakan tempat yang tidak dilalui oleh tamu hotel. Pemeliharaan ideal dilakukan pada saat chief garden melakukan pengecekan di lapangan, jika ditemukan ada yang tidak sesuai dengan konsep yang ditentukan maka chief garden akan langsung menghubungi koordinator untuk dilakukan perbaikan. Pemeliharaan fisik bertujuan untuk menjaga keindahan, keasrian, kenyamanan, dan keamanan pada taman. Oleh karena itu, pemeliharaan fisik dilakukan setiap hari. Pemeliharaan fisik yang dilakukan setiap hari seperti: menyapu, menyiram, memangkas rumput, pendagiran, pemeliharaan hardscape. Dan juga ada pemeliharaan fisik yang dilakukan secara berkala yaitu memupuk dan mengendalikan hama.

\subsection{Aktifivitas Pemeliharaan Taman}

Hotel Melia Bali memiliki 42 tenaga kerja taman dengan rincian 1 koordinator, 1 teknisi, 3 supervisor, 3 tukang panjat, 2 tukang potong rumput, 27 gardener, dan 5 beach cleaner yang semuanya disediakan oleh pihak kontraktor. Para tenaga pekerja memiliki waktu kerja selama 8 jam termasuk di dalamnya 1 jam untuk istirahat. Para tenaga gardener bekerja sesuai dengan shift meraka masing-masing. Gardener memiliki tiga shift yaitu pukul 06.00-14.00, pukul 07.00-15.00, dan 08.00-16.00.

\subsubsection{Pembersihan Atau Penyapuan}

Pada Hotel Melia Bali kegiatan penyapuan dibedakan menjadi dua macam yaitu terdapat area berumput dan area perkerasan. Kegiatan penyapuan atau pembersihan ini dilakukan pada pukul 06.00 wita sampai dengan pukul 08.00 wita atau dapat dibilang kegiatan penyapuan ini berlangsung sekitar $2 \mathrm{jam}$. Jadwal ini berlaku untuk semua area atau section yang ada sehingga para pekerja akan mulai melakukan kegiatan 
pembersihan pada pukul 06.00 dan selesai pada 08.00 dan akan dilanjutkan dengan kegiatan berikutnya. Dalam melakukan kegiatan penyapuan para pekerja menggunakan alat-alat seperti sapu lidi bertangkai, garu, pengki, dan gerobak sampah. Alat-alat yang digunakan untuk melakukan penyapuan disediakan oleh pihak hotel bukan dari pihak kontraktor. Kegiatan penyapuan dapat dilihat pada Gambar 4.
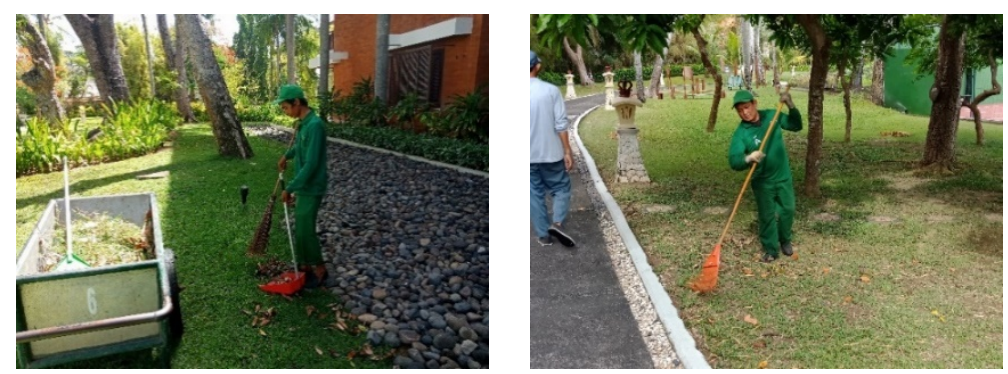

Gambar 4. Kegiatan Penyapuan atau Pembersihan Area Berumput

Arifin dan Arifin (2005) menjelaskan bahwa kegiatan penyapuan dapat dikatakan efektif dan efisien

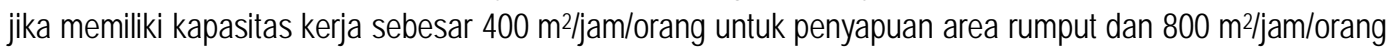
untuk penyapuan area perkerasan. Kapasitas kerja penyapuan atau pembersihan area perkerasan yang dilakukan adalah sebesar 1.368 m²/jam/orang atau 171\% lebih besar 71\% dari kapasitas kerja ideal yaitu 800 $\mathrm{m}^{2} /$ jam/orang. Sedangkan untuk penyapuan atau pembersihan area berumput adalah sebesar 724 $\mathrm{m}^{2} /$ jam/orang atau $181 \%$ lebih besar $81 \%$ dari kapasitas kerja ideal yaitu $400 \mathrm{~m} 2 /$ jam/orang. Hal ini disebabkan oleh beberapa hal seperti, pertama karena jumlah tanaman penyumbang sampah daun/bij/buah tidaklah banyak karena dari pengamatan, karena didominasi oleh palem. Kedua para pekerja sudah mendapatkan pelatihan sebelum melakukan kegiatan pemeliharaan sehingga mereka tidak mengalami kesulitan. Ketiga, para pekerja melakukan pemeliharaan pada area yang sama setiap harinya sehingga mereka sudah mengenali atau paham terhadap area mereka sendiri. Keempat, setiap pekerjaan memiliki jam kerjanya masing-masing dan harus sesuai. Jika terjadi keterlambatan maka akan mendapat teguran dari teknisi atau kordinator lapangan.

\subsubsection{Penyiraman}

Kegiatan penyiraman dapat dibedakan menjadi dua macam yaitu penyiraman menggunakan sprinkle dan penyiraman menggunakan selang plastik. Gardener biasanya melakukan penyiraman rumput dan tanaman-tanaman menggunakan sprinkle pada pukul 06.00-08.00 wita dan melakukan penyiraman dengan selang plastik untuk area atau tanaman yang tidak terkena sprinkle seperti semak dan pohon di pinggir-pinggir pada pukul 08.00-10.00 wita. Penyiraman dilakukan setiap hari saat musim kemarau, jika musim hujan penyiraman dilakukan dengan menyesuaikan terhadap kondisi tanah jika tanah terlihat kering maka dilakukan penyiraman begitu sebaliknya jika terlihat basah maka tidak dilakukan penyiraman. Perintah penyiraman ini ditentukan oleh koordinator.

Arifin dan Arifin (2005) menjelaskan bahwa kegiatan penyiraman dapat dikatakan efektif dan efisien jika memiliki kapasitas kerja sebesar $500 \mathrm{~m} 2 /$ jam/orang untuk penyiraman rumput menggunakan sprinkle, sebesar $150 \mathrm{~m} 2 /$ jam/orang untuk penyiraman tanaman penutup tanah dan rumput dengan menggunakan selang plastik, dan sejumlah 15 pohon untuk penyiraman pohon menggunakan selang plastik. Kapasitas penyiraman rumput yang menggunakan sprinkle yang dilakukan adalah sebesar 570 m²/jam/orang atau $114 \%$ lebih besar $14 \%$ dari kapasitas ideal yaitu $500 \mathrm{~m}^{2} / \mathrm{jam} /$ orang. Hal ini disebabkan karena dalam penyiraman menggunakan lebih dari satu sprinkle yang membuat kegiatan lebih cepat walaupun dikerjakan bersamaan dengan kegiatan penyapuan tetapi tetap efisien. Penyiraman penutup tanah dan pohon menggunakan selang plastik yang dilakukan adalah sebesar 181,5 m²/jam/orang atau $121 \%$ lebih besar $21 \%$ dari kapasitas ideal yaitu $150 \mathrm{~m}^{2} /$ jam/orang untuk penyiraman penutup tanah dan sebanyak 18 pohon atau $124 \%$ lebih besar $24 \%$ dari kapasitas ideal yaitu 15 pohon. Hal ini disebabkan karena para pekerja menggunakan ukuran selang yang lebih besar (1 inci) dari pada yang digunakan oleh standar kapasitas (3/4 inci) yang ada dan juga dengan debit air hampir 0,5 liter/detik. Penyiraman menggunakan selang memiliki 
waktu tersendiri yaitu setelah kegiatan penyapuan dan penyiraman rumput menggunakan sprinkle sehingga para pekerja bisa fokus pada kegiatan ini saja. Kegiatan penyiraman dapat dilihat pada Gambar 5.
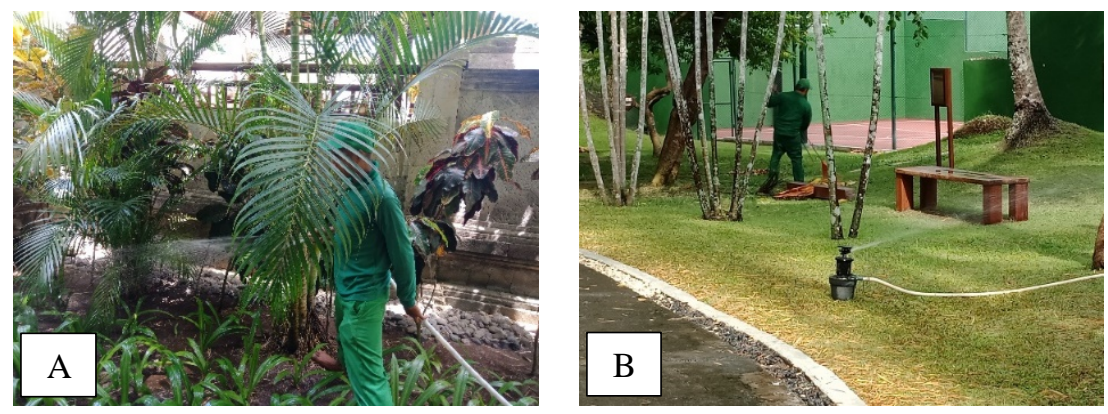

Gambar 5. Penyiraman Menggunakan (a) Selang dan (b) Sprinkle

\subsubsection{Pemangkasan}

Pemangkasan rumput gardener menggunakan alat pemotong rumput gendong dan dorong, untuk pemangkasan semak mereka menggunkan sabit, dan untuk pemangkasan pohon mereka menggunakan gergaji mesin. Kegiatan pemangkasan rumput dibagi dalam beberapa waktu yaitu, untuk pemangkasan rumput menggunakan mesin gendong dan mesin dorong dilakukan 2-3 kali. Sedangkan untuk pemangkasan semak dilakukan setiap hari berbarengan dengan penggemburan tanah dan penyiangan gulma. Pemangkasan pohon dilakukan apabila sudah terlihat perlu dilakukannya pemangkasan maka akan dilakukan pemangkasan.
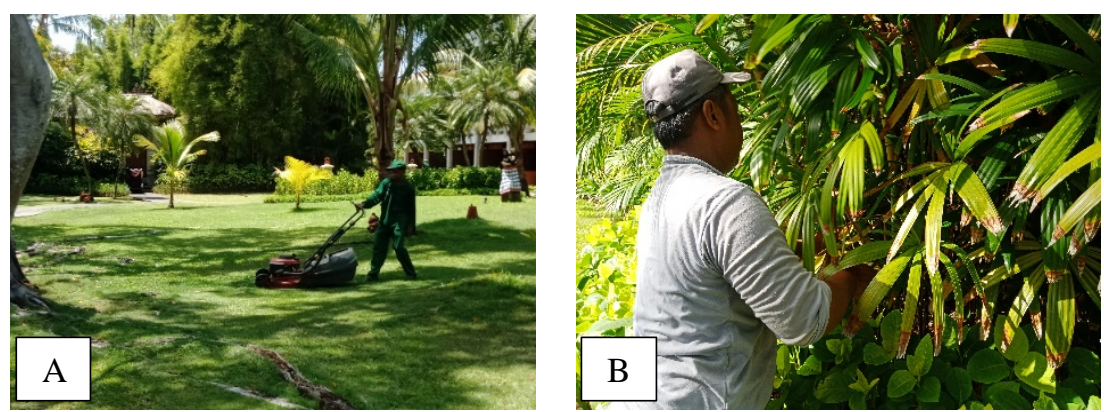

Gambar 6. Kegiatan (a) Pemangkasan Rumput Menggunakan Mesin Dorong dan (b) Pemangkasan Semak

Arifin dan Arifin (2005) menjelaskan bahwa kegiatan pemangkasan dikatakan efektif dan efisien jika memiliki kapasitas kerja sebesar $500 \mathrm{~m}^{2}$ /jam/orang untuk pemangkasan rumput yang menggunakan mesin dorong dan sebesar $250 \mathrm{~m}^{2} /$ jam/orang untuk pemangkasan rumput yang menggunakan mesin gendong. Kapasitas pemangkasan rumput yang dilakukan adalah sebesar $400 \mathrm{~m}^{2} /$ jam/orang atau $80 \%$ lebih kecil $20 \%$ dari kapasitas ideal untuk pemotongan rumput menggunakan mesin dorong ini disebabakan oleh lahan yang bergelombang dan juga akar pohon yang muncul ke permukaan. Tetapi, kekurangan ini ditutupi dengan mengerahkan 2 pegawai untuk melakukan pemotongan rumput sehingga mendapatkan hasil 2 kali lipat. Pemotongan rumput menggunakan mesin gendong sebesar 250 m²/jam/orang atau $100 \%$ sesuai dengan kapasitas ideal untuk. Hal ini disebabkan karena dalam pemangkasan rumput dilakukan oleh pekerja khusus yang sudah terlatih dalam melakukan pemangkasan rumput.

\subsubsection{Penggemburan Tanah dan Penyiangan Gulma}

Kegiatan penggemburan tanah dan penyiangan gulma dilakukan setiap hari agar pertumbuhan dan perkembangan tanaman tidak terganggu sehingga tanaman tumbuh dan berkembang secara maksimal. Kegiatan ini dilakukan berbarengan dengan pemangkasan semak yaitu pada pukul 12.00 sampai dengan pukul 14.00. Dalam kegiatan penggemburan tanah dan penyiangan gulma para pekerja menggunakan cangkul dan kored. 
Arifin dan Arifin (2005) menjelaskan bahwa kegiatan penggemburan tanah dan penyiangan gulma dikatakan efektif dan efisien jika memiliki kapasitas kerja sebesar $40 \mathrm{~m}^{2} /$ jam/orang dengan menggunakan cangkul dan kored. Kapasitas penggemburan tanah dan penyiangan gulma yang dilakukan adalah sebesar $52,4 \mathrm{~m}^{2} / \mathrm{jam} /$ orang atau $131 \%$ lebih besar dibandingkan dengan kapasitas ideal yaitu $40 \mathrm{~m}^{2} / \mathrm{jam} /$ orang. Hal ini disebabkan karena para perkerja sudah mendapat pelatihan terlebih dahulu serta melakukannya setiap hari sehingga sudah mahir dengan kegiatan yang dilakukan. Faktor lain yang berkontribusi pada luas area yang mampu dikerjakan perjam/orangnya adalah adanya bantuan dari para pekerja yang tidak memiliki kesibukan sehingga dapat mempercepat kegiatan.
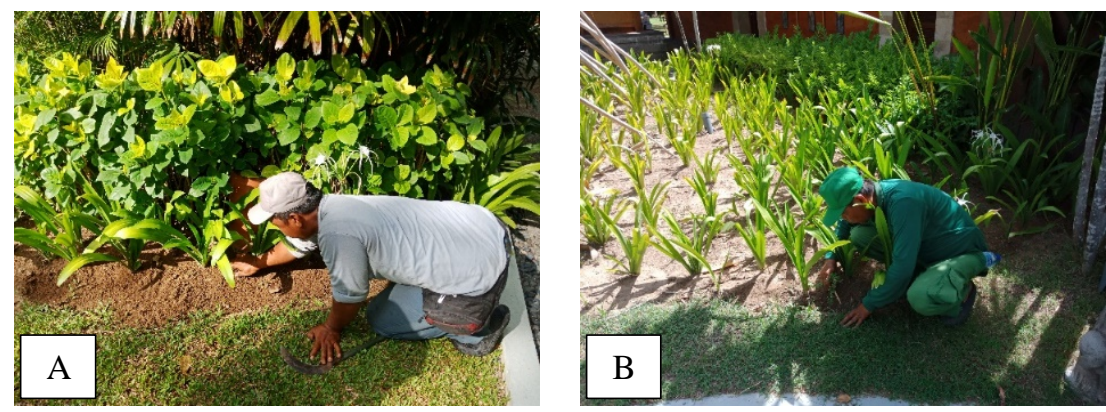

Gambar 7. Kegiatan (a) Penggemburan tanah dan (b) Penyiangan Gulma

\subsubsection{Pemupukan}

Pupuk yang digunakan adalah pupuk organik dan pupuk anorganik. Pupuk organik yang digunakan adalah pupuk kandang dan pupuk anorganik yang digunakan adalah ZA dan NPK. Kontraktor memberikan sebanyak $3 \mathrm{~m}^{3}$ pupuk kandang, $150 \mathrm{~kg}$ ZA dan $50 \mathrm{~kg}$ NPK untuk setiap bulannya. Dengan pembagian pupuk ZA untuk rumput, pupuk NPK untuk tanaman di dalam pot dan tanaman air, pupuk kandang untuk semua tanaman yang ditanam langsung di tanah dan tanaman di dalam pot, dan untuk pohon-pohon besar sangat jarang diberikan pupuk. Tetapi pupuk yang didapatkan tersebut ternyata tidak cukup untuk seluruh tanaman yang ada sehingga dilakukan pembagian untuk pemupukkan. Jadi setiap bulannya pemupukkan dilakukan hanya untuk 4 section saja, dan karena ada 12 section untuk kembali ke section pertama dibutuhkan waktu 3 bulan sehingga di simpulkan jika pemupukkan setiap 3 bulan sekali.

\subsubsection{Pengendalian Hama dan Penyakit Tanaman}

Pengendalian hama dan penyakit tanaman dilakukan 1-2 kali perbulannya. Jika musim hujan pengendalian hama dan penyakit tanaman dilakukan 1 kali dan jika musim kemarau pengendalian hama dan penyakit tanaman dilakukan 2 kali. Hal yang perlu diperhatikan dalan melakukan pengendalian hama dan penyakit tanaman di hotel adalah arah angin dan hujan. Hama yang biasanya muncul adalah ulat, wereng, belalang, bekicot, kumbang, dan keong.

Pestisida yang digunakan adalah Dursban ditambah perekat untuk hama wereng, ulat, dan belalang karena mengandung senyawa klorpirifos yang merupakan racun jika masuk ke tubuh hama, moluskisida Siputox dengan bahan aktif metaldehyd untuk mengendalikan muluska, Curacron untuk hama kumbang karena memiliki kandungan Profenofos yang merupakan bahan aktif dan baunya dapat menarik perhatian kumbang, dan Bentan untuk hama keong karena merupakan moluskisida yang sama dengan siputox tapi mudah bercampur atau larut di air. Dalam melakukan pengendalian hama dan penyakit tanaman biasanya dilakukan selama tiga hari dan 2 jam/orang untuk perharinya. Alat yang digunakan untuk penyemprotan hama adalah sprayer gendong. Penyakit tanaman yang sering terjadi adalah busuk batang dan busuk akar. Penyakit ini disebabkan oleh lokasi tanaman yang tidak sesuai dengan habitatnya. Tanaman yang telah terkena penyakit akan langsung diganti dengan tanaman yang baru.

\subsubsection{Pemeliharaan Hardscape}

Gardener tidak memiliki tugas pokok untuk melakukan perawatan terhadap hardscape, gardener hanya akan melakukan melakukan perawatan hardscape jika dimintai bantuan oleh pihak hotel. Hardscape yang paling sering diminta untuk dilakukan perawatan adalah kolam ikan atau mereka sering menyebutnya kolam tunjung atau teratai. Hal ini dikarenakan kolam ikan memiliki luas $3.538 \mathrm{~m}^{2}$ dan juga letak nya berada di 
area yang sering dilewati oleh tamu sehingga diperlukan perawatan setiap harinya. Perawatan yang biasanya dilakukan adalah membersihkan daun-daun yang berguguran di kolam, memangkas daun-daun tanaman yang layu, dan pengecekan hama pada tanaman yang biasanya adalah keong.
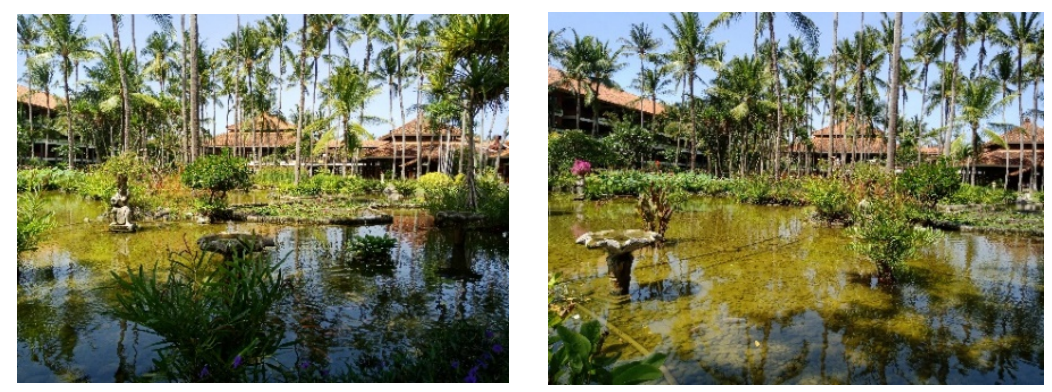

Gambar 8. Lagoon Milik Hotel Melia Bali

\subsubsection{Kapasitas Kerja Pemeliharaan Taman}

Kapasitas kerja pemeliharaan taman yang dimiliki oleh gardener yang diperoleh berdasarkan pengamatan yang dilakukan di lapangan. Nilai kapasitas kerja gardener dibandingkan dengan nilai kapasitas kerja Arifin dan Arifin (2005) disajikan pada Tabel 4 berikut ini.

Tabel 4. Kapasitas Kerja Pemeliharaan Taman Hotel Melia Bali

\begin{tabular}{|c|c|c|c|c|c|}
\hline No & Kegiatan & Standar & Kinerja & $(\%)$ & Pembahasan \\
\hline 1 & $\begin{array}{l}\text { Penyapuan atau } \\
\text { pembersihan area } \\
\text { berumput }\end{array}$ & $400 \mathrm{~m}^{2}$ & $724 \mathrm{~m}^{2}$ & $181 \%$ & $\begin{array}{l}\text { 1. Dilakukan } 1 \text { orang dengan rata- rata usia } 30 \\
\text { tahun. } \\
\text { 2. Alat sapu lidi bertangkai, pengki, dan gerobak } \\
\text { sampah. } \\
\text { 3. Dilakukan saat kondisi kering. } \\
\text { 4. Tanaman didominasi oleh tanaman palem. } \\
\text { 5. Pekeria sudah mendapatkan pelatihan. }\end{array}$ \\
\hline 2 & $\begin{array}{l}\text { Penyapuan atau } \\
\text { pembersihan area } \\
\text { perkerasan }\end{array}$ & $800 m^{2}$ & $1368 m^{2}$ & $171 \%$ & $\begin{array}{l}\text { 6. Melakukan pekerjaan pada area yang sama } \\
\text { setiap harinya. } \\
\text { 7. Mengutamakan sampah anorganik. }\end{array}$ \\
\hline 3 & $\begin{array}{l}\text { Penyiraman rumput } \\
\text { dengan sprinkle }\end{array}$ & $500 \mathrm{~m}^{2}$ & $570 \mathrm{~m}^{2}$ & $114 \%$ & $\begin{array}{l}\text { 1. Dilakukan } 1 \text { orang dengan rata- rata usia } 30 \\
\text { tahun. }\end{array}$ \\
\hline 4 & $\begin{array}{l}\text { Penyiraman semak } \\
\text { dengan selang } \\
\text { plastik }\end{array}$ & $150 \mathrm{~m}^{2}$ & $181,5 \mathrm{~m}^{2}$ & $121 \%$ & $\begin{array}{l}\text { 2. Alat sprinkle tanam, sprinkle pindah, selang } \\
\text { plastik } \\
\text { 3. Dilakukan saat kondisi kering }\end{array}$ \\
\hline 5 & $\begin{array}{l}\text { Penyiraman pohon } \\
\text { dengan selang } \\
\text { plastik }\end{array}$ & 15 pohon & 18 pohon & $124 \%$ & $\begin{array}{l}\text { 4. Menggunakan lebih dari satu sprinkle } \\
\text { 5. Debit air } 1 \text { liter/2-3 detik } \\
\text { 6. Penyiraman dilakukan hingga air sedikit } \\
\text { menggenang ditanah. }\end{array}$ \\
\hline 6 & $\begin{array}{l}\text { Pemangkasan } \\
\text { rumput dengan } \\
\text { mesin dorong }\end{array}$ & $500 \mathrm{~m}^{2}$ & $400 \mathrm{~m}^{2}$ & $80 \%$ & $\begin{array}{l}\text { 1. Dilakukan } 1 \text { orang dengan rata- rata usia } 30 \\
\text { tahun. } \\
\text { 2. Alat pemotong rumput dorong dan gendong. }\end{array}$ \\
\hline 7 & $\begin{array}{l}\text { Pemangkasan } \\
\text { rumput dengan } \\
\text { mesin gendong }\end{array}$ & $250 \mathrm{~m}^{2}$ & $250 \mathrm{~m}^{2}$ & $100 \%$ & $\begin{array}{l}\text { 3. Lahan bergelombang dan akar pohon muncul } \\
\text { kepermukaan } \\
\text { 4. Rumput dipotong hingga setinggi } 3-4 \mathrm{~cm} \text {. }\end{array}$ \\
\hline 8 & $\begin{array}{l}\text { Penggemburan } \\
\text { tanah dan } \\
\text { penyiangan gulma }\end{array}$ & $40 m^{2}$ & $52 \mathrm{~m}^{2}$ & $131 \%$ & $\begin{array}{l}\text { 1. Dilakukan } 1 \text { orang dengan rata- rata usia } 30 \\
\text { tahun. } \\
\text { 2. Alat kored dan cangkul. } \\
\text { 3. Dilakukan setiap hari. } \\
\text { 4. Dilakukan setelah melakukan penyiraman. } \\
\text { 5. Kadang-kadang dibantu oleh pekerja yang tidak } \\
\text { memiliki kesibukan. } \\
\text { 6. Penggemburan dilakukan satu jengkal ke dalam } \\
\text { tanah. }\end{array}$ \\
\hline
\end{tabular}


Berdasarkan hasil perbandingan dari standar kapasitas kerja dengan kinerja gardener Hotel Melia Bali menunjukan jika kinerja para gardener melebihi standar kapasitas kerja yang dibuat oleh Arifin dan Arifin (2005) kecuali pemotongan rumput menggunakan mesin dorong hanya mencapai $80 \%$ dari standar. Hal ini diduga dipengaruhi oleh beberapa faktor, baik yang berfisat teknis maupun non teknis. Faktor yang bersifat teknis antara lain pelatihan dan pendidikan, alat yang digunakan prima dan sesuai untuk kerja, terdapat SOP pemeliharaan taman. Sementara faktor non teknis yang diperkirakan mempengaruhi adalah perilaku disiplin gardener, terdapat motivasi kerja, lingkungan kerja, insentif dari pihak hotel berdasarkan hasil kerja gardener. Ini merupakan faktor dari hasil kinerja para gardener dapat melebihi dari standar kapasitas kerja yang ada.

\section{Simpulan}

Berdasarkan hasil penelitian yang dilakukan di Hotel Melia Bali dapat disimpulkan sebagai berikut:

1. Sistem pemeliharaan yang digunakan Hotel Melia Bali adalah sistem alih daya, dimana pihak hotel menggunakan jasa kontraktor untuk memeliharan taman yang mereka miliki. PT. Danudewa Sarwadha Nawacandra selaku kontraktor yang digunakan, yang dimana pihak kontraktor yang menyiapkan tenaga kerja serta beberapa kebutuhan yang diperlukan seperti pakaian, alat, dan bahan. Pemeliharaan taman menggunakan pemeliharaan ideal dan pemeliharaan fisik. Gardener juga memiliki jadwal pemeliharaan yang digunakan oleh para pekerja namun mereka tidak memilikinya dapat bentuk tertulis sehingga hal yang harus dikerjakan oleh para pekerja hanya diberitahukan secara lisan.

2. Kinerja para gardener tergolong sangat memuaskan, itu dapat dilihat dari hasil perhitungan kinerja para gardener dengan standar kapasitas kerja menunjukkan jika kinerja para gardener melebihi dari standar kapasitas kerja. Hal ini dipengaruhi oleh beberapa faktor, baik yang berfisat teknis maupun non teknis. Faktor yang bersifat teknis antara lain pelatihan dan pendidikan, alat yang digunakan prima dan sesuai untuk kerja, terdapat SOP pemeliharaan taman. Sementara faktor non teknis yang diperkirakan mempengaruhi adalah perilaku disiplin gardener, terdapat motivasi kerja, lingkungan kerja, insentif dari pihak hotel berdasarkan hasil kerja gardener. Ini semua merupakan kunci dari hasil kinerja para gardener yang ideal di Hotel Melia Bali.

\section{Daftar Pustaka}

Arifin, H.S. \& N.H.S. Arifin. 2005. Pemeliharaan Taman (Edisi Revisi). Penebar Swadaya, Jakarta. Google Earth. https://earth.google.com/web/. Di akses Maret 2019

Hotel Melia Bali. 2018. Kebutuhan Tanaman. Bali.

Istacahyani, I.A.M. 2018. Evaluasi Pemeliharaan Taman Pada Kawasan Bali Tropic Resort And Spa Kabupaten Badung. Bali (ID): Universitas Udayana.

Pranata, N.D. 2018. Efisiensi Pemeliharaan Taman: Studi Kasus Di Hotel Oberoi Bali. Bali (ID): Universitas Udayana.

Sudjana, D. 2001. Metode Statistika. Tarsito. Bandung.

Sugiyono. 2014. Metode Penelitian Pendidikan: Pendekatan Kuantitatif, Kualitatif dan R\&D Cet.

Supihati. 2014. Analisis Faktor-Faktor Yang Mempengaruhi Kinerja Karyawan Perusahaan Sari Jati Di Sragen.

Suryana. 2012. Metodologi Penelitian. Model Praktis Penelitian Kuantitatif dan Kualitatif. 